\title{
Correction to: Neurological complications of pediatric cancer
}

\section{Caren Armstrong ${ }^{1} \cdot$ Lisa R. Sun ${ }^{1}$}

Published online: 12 February 2020

(C) Springer Science+Business Media, LLC, part of Springer Nature 2020

Correction to: Cancer and Metastasis Reviews

$$
\text { https://doi.org/10.1007/s10555-020-09847-0 }
$$

The authors have noticed a typographical error in the published article. There should be no subheading after the section "5.4 Sensory symptoms and weakness localizing to the peripheral nervous system."

The original article has been corrected.

Publisher's note Springer Nature remains neutral with regard to jurisdictionalclaims in published maps and institutional affiliations.

The online version of the original article can be found at https://doi.org/ 10.1007/s10555-020-09847-0

Lisa R. Sun

1sun20@jhmi.edu

1 Department of Neurology, Johns Hopkins Hospital, 200 N Wolfe St Suite 2158, Baltimore, MD 21287, USA 